\title{
Cuidar de crianças com necessidades especiais de saúde: desafios para as famílias e enfermagem pediátrica ${ }^{1}$
}

\section{Caring of children with special health care needs: challenges to families and pediatric nursing}

\author{
Cuidar de niños con necesidades especiales de salud: \\ desafíos para las familias y la enfermería pediátrica
}

\author{
Eliane Tatsch Neves', Ivone Evangelista Cabral"
}

\begin{abstract}
${ }^{1}$ Este artigo é um recorte da tese de doutorado intitulada: “O empoderamento de cuidadoras de crianças com necessidades especiais de saúde: interfaces com o cuidado de enfermagem", apresentada na Escola de Enfermagem Anna Nery da Universidade Federal do Rio de Janeiro (EEAN/UFRJ), em julho de 2007.

' Enfermeira pediatra. Doutora em Enfermagem. Docente do Departamento de Enfermagem e do Mestrado em Enfermagem da Universidade Federal de Santa Maria (UFSM). Bolsista CAPES. E-mail: elianev@terra.com.br.

"Enfermeira pediatra. Doutora em Enfermagem. Docente do Departamento Materno-Infantil da EEAN/UFRJ. Pesquisadora do CNPq/FAPERJ. Email: icabral44@hotmail.com.
\end{abstract}

\section{RESUMO}

Crianças com necessidades especiais de saúde (CRIANES) demandam cuidados especiais de saúde no domicílio, caracterizados como de natureza contínua e complexa. Objetivou-se descrever e discutir os desafios determinados por esses cuidados para as cuidadoras de CRIANES no domicílio. Pesquisa qualitativa realizada em hospital de ensino do sul do Brasil, em dezembro de 2004, tendo como fonte de dados: entrevista, relatório da dinâmica de criatividade e sensibilidade Corpo Saber desenvolvida com quatro cuidadoras e prontuário de cinco crianças em atendimento. Os dados foram analisados pelo método da Análise de Discurso francesa. As mulheres desvelaram a natureza complexa do cuidado às CRIANES e a relevância de realizá-lo com base em saberes e práticas que não pertencem ao seu cotidiano existencial. Elas situaram esse cuidado como de sobrevivência, (sobre)natural e singular devido a sua complexidade, elevada demanda e dedicação. Prioritariamente, todas as ações cuidativas implementadas eram preservadoras da vida. Conclui-se que é preciso incluir as famílias das CRIANES na assistência de enfermagem no intuito de ampliar o poder de negociação dessas mulheres para além da sobrevivência. Assim, as CRIANES apresentam desafios a Enfermagem Pediátrica, tendo em vista as diferentes demandas de cuidados tanto em nível hospitalar quanto familial e comunitário.

Descritores: Enfermagem pediátrica; Cuidadores; Saúde da criança; Educação em saúde.

\section{ABSTRACT}

Children with special health care needs (CSHN) demand continuous and complex special health care at home. Qualitative research was applied to describe and discuss the challenges determined for these caring to CSHN's caregivers at home. Four female caregivers of the CSHN in a room-in at teaching hospital in the southern Brazil on December of 2004 were interviewed and participated in group dynamics of the creative-sensitive method. And charts of these children were analyzed. French discourse analysis was applied to the empirical data. The caregivers unveil the complex nature of the CSHN'S care and the relevance to do that based on knowledge and practices which are no included in their existential daily life. This caring was characterized as a survival care, (super) natural and singular due to it complexity, high demand and dedication. As a priority, all care actions were in order to preserve of the child's life. In conclusion, it is necessary to include these relative caregivers in the nursing care, aiming to amplify the negotiation power of these women beyond the survival of them. In this way, the CSHN present challenges to pediatric nursing due to care demands in different sceneries such as hospital, family and community.

Descriptors: Pediatric nursing; Caregivers; Health education; Child health.

\section{RESUMEN}

Niños con necesidades especiales de salud (NNES) exigen cuidados especiales de salud domiciliaria, caracterizados por ser de naturaleza continua y compleja. Objetivó-se describir y discutir los desafíos que conllevan estos cuidados para las cuidadoras familiares de NNES. Estudio cualitativo realizado hospital universitario del sur de Brasil en diciembre de 2004 teniendo como fuente de datos: la entrevista, un informe de la dinámica de creatividad y sensibilidad Cuerpo Saber desarrollada con cuatro cuidadoras y el prontuario de cinco niños en atención. Los datos fueron analizados por el método del análisis del discurso francés. Las mujeres desvelaron la naturaleza compleja de los cuidados a los NNES y la relevancia de realizarlo con base en los saberes y prácticas que no pertenecen a su cotidiano existencial. Ellas clasificaron ese cuidado como de supervivencia, (sobre) natural y singular debido a su complejidad, elevada demanda y dedicación. En su mayoría, todas las acciones cuidativas implementadas eran preservadoras de la vida. Se concluyó que es necesario incluir las familias de los NNES en los cuidados de enfermería, ampliando el poder de negociación de las mujeres. Así, NNES presentan desafíos a la Enfermería pediátrica, considerando las diferentes demandas de los cuidados hospitalarios, familiares e comunitários.

Descriptores: Enfermería pediátrica; Cuidadores; Educación en salud; Salud del niño. 


\section{NTRODUÇÃO}

Comparando-se as Taxas de Mortalidade Infantil (TMI), de 1984 (70,9 por mil nascidos vivos) com 2004 (22,5 por mil nascidos vivos) ${ }^{(1)}$, percebe-se uma mudança no perfil epidemiológico da infância brasileira. Enquanto no primeiro momento, as doenças imunopreveníveis contribuíram expressivamente para o quadro de morbimortalidade, no segundo, as afecções perinatais desenham uma nova tendência neste quadro. Três fatores determinantes contribuíram para essa mudança. Primeiramente, a melhoria das condições ambientais e nutricionais da população infantil brasileira; segundo, a implementação de programas, estratégias e ações de saúde direcionadas ao quadro de morbimortalidade infantil, como por exemplo, o impacto do Programa Nacional de Imunização (PNI) sobre a redução das doenças infecciosas e imunopreveníveis; e, terceiro, a incorporação de novas tecnologias na recuperação das doenças infantis por causas congênitas e adquiridas ${ }^{(2-3)}$.

Em contrapartida à maior sobrevivência infantil frente à prematuridade, às malformações congênitas, doenças crônicas e traumas, houve um crescimento de sobreviventes com sequelas advindas da recuperação dos quadros agudos de doenças e/ou do processo terapêutico.

Em todo o mundo, os benefícios da rápida evolução da tecnologia de medicamentos e equipamentos gerou uma nova clientela, denominada pelo Maternal and Health Children Bureau (Estados Unidos), pela primeira vez, em 1998, de Children with Special Health Care Needs $(\mathrm{CSHCN})^{(4)}$. Elas representam um conjunto de crianças que demandam cuidados especiais de saúde, de natureza temporária ou permanente, com uma pluralidade de diagnósticos médicos, dependência contínua dos serviços de saúde e de diferentes profissionais devido à fragilidade clínica ${ }^{(4-5)}$.

No Brasil, elas foram denominadas de Crianças com Necessidades Especiais de Saúde (CRIANES) ${ }^{(6)}$, tendo como agravante à fragilidade clínica dois importantes complicadores: a vulnerabilidade social e a ausência de políticas públicas específicas direcionadas para esse grupo populacional ${ }^{(5)}$. Por exemplo, no Rio de Janeiro (Brasil), um estudo apontou que $74,2 \%$ dos bebês egressos da terapia intensiva neonatal apresentavam alguma necessidade especial de saúde; e no sul do Brasil (Santa Maria RS) o índice de necessidades especiais atribuídas a intercorrências no período perinatal foi de $58,5 \%^{(7)}$.

No que se referem à fragilidade clínica das CRIANES brasileiras, os distúrbios respiratórios são apontados como a causa principal de internação hospitalar. Dados do Ministério da Saúde relacionados com a hospitalização de crianças menores de cinco anos indicam que só no ano de 2004 , elas representaram $45 \%$ das internações nos hospitais do Sistema Único de Saúde (SUS). A média de internação foi de 15 dias $^{(1)}$. Outro estudo apontou que $6,3 \%$ crianças egressas da terapia intensiva pediátrica pertenciam ao grupo das CRIANES ${ }^{(8-9)}$.

No conjunto das vulnerabilidades sociais que aumentam a exposição das CRIANES ao adoecimento e à cronicidade, está a contribuição do componente neonatal na TMI. Esta contribuição relaciona-se ao aumento da taxa de morbidade por afecções perinatais que, na contramão do movimento decrescente da TMI no Brasil, encontra-se em ritmo crescente. As condições de saúde da mulher, da gestação, do parto e do nascimento permanecem como fatores contribuintes para que as afecções perinatais tornem o componente neonatal um grande desafio para a problemática de saúde e doença dos menores de um ano.

Outro achado significativo registrado nos estudos brasileiros sobre CRIANES é a particularidade das demandas de cuidados situando-as como de desenvolvimento, tecnológicos, medicamentosos e habituais modificados ${ }^{(9)}$. No primeiro, estão incluídas as crianças com disfunção neuromuscular que requerem reabilitação psicomotora e social. No segundo, as crianças dependentes de tecnologia (cateter semi-implantável, bolsas de colostomia, ureterostomia, cânula de traqueostomia etc). No terceiro segmento, estão as fármacodependentes (antirretrovirais, cardiotônicos, neurolépticos etc). No último, as crianças que dependem de modificações na forma habitual de cuidar incluindo a realização de tarefas comuns no dia-a-dia ${ }^{(7,10-11)}$.

As crianças com necessidades especiais de saúde, quando no domicílio, demandam cuidados contínuos de natureza complexa, constituindo-se em desafios para os seus cuidadores familiares. Neste contexto, há a necessidade de se mediar práticas de cuidado, tendo por base os saberes fundamentais da Enfermagem. Portanto, destaca-se a educação em saúde como uma estratégia de intervenção importante, cujas premissas apontam para o conhecimento dos familiares cuidadores, alvo da ação educativa, e de suas demandas de aprendizagem para cuidar de uma CRIANES. Desta forma, com o objetivo de descrever e discutir os desafios determinados por esses cuidados para as cuidadoras familiares de CRIANES no domicílio questionou-se: quais desafios as CRIANES apresentam no cuidado domiciliar para os familiares cuidadores?

\section{MATERIAIS E MÉTODOS}

Trata-se de um estudo qualitativo exploratório descritivo desenvolvido em um hospital público de grande porte, federal, destinado ao ensino, pesquisa e assistência à comunidade, que atende demandas de toda a região centro-oeste do Estado do Rio Grande do Sul. O hospital é referência em alta complexidade, 
sendo o único hospital público da região que possui Unidade de Terapia Intensiva Neonatal e Pediátrica.

Constituíram-se, como fontes de dados, os prontuários de cinco crianças e a entrevista semiestruturada com quatro cuidadoras, sendo que uma delas possui dois filhos CRIANES. Estas informações somaram-se ao relatório da dinâmica de criatividade e sensibilidade (DCS) Corpo Saber realizada com essas quatro cuidadoras em dezembro de 2004.

Na DCS Corpo Saber, apresentou-se aos sujeitos da pesquisa um cartaz com o desenho da silhueta de uma criança e solicitou-se que, com canetas coloridas, eles registrassem palavras-chave indicativas das ações de cuidar, desempenhadas por eles. A questão geradora de debate foi: "Como você cuida de seu filho em casa após a alta do hospital?" Porém, as cuidadoras optaram por fazer, cada uma, o seu próprio desenho em folhas de papel $A_{4}$ para representar o cuidado. Com isso, elas trabalharam individualmente, construindo a sua produção artística (PA) representativa do cuidado domiciliar.

A implementação da Dinâmica Corpo Saber orientou-se pelas diretrizes do método criativo e sensível, ou seja, combinou procedimentos de coleta de dados típicos da pesquisa qualitativa tradicional (observação, entrevista e discussão de grupo) com as produções artísticas. Embora, a concepção grupal imanente a DCS seja de pluralidade, a singularidade de cada participante foi preservada pelo espírito democrático e participativo(11).

Por essa razão, a DCS foi desenvolvida em cinco momentos ${ }^{(11)}$ : primeiro momento, as participantes do grupo se apresentaram, e o primeiro autor (pesquisador de campo) explicou o que se esperava com o encontro e com o desenvolvimento da dinâmica; no segundo, os materiais utilizados na dinâmica foram disponibilizados às participantes, a questão geradora de debate foi introduzida pelo pesquisador, e as participantes realizaram o trabalho individual ou coletivo. No terceiro momento, as participantes apresentaram as suas produções artísticas individuais ou coletivas, socializaram o que foi produzido. No quarto momento, os temas geradores foram decodificados em subtemas durante a análise coletiva e a discussão grupal. No último momento, procedeu-se à síntese temática dos temas e subtemas, bem como à validação dos dados.

Os dados produzidos foram analisados pelo método da Análise de Discurso francesa como método de leitura e interpretação dos dados. A opção por essa vertente de análise deveu-se ao fato de a leitura flutuante das entrevistas e do relatório da DCS apontar para um discurso marcado pela história existencial das mulheres, como uma prática de cuidado culturalmente naturalizada(12).

A primeira etapa da análise constituiu-se em conferir materialidade linguística ao texto. Para tanto, foram utilizados recursos ortográficos, tais como: /: pausa reflexiva curta; //: pausa reflexiva longa;///: pausa reflexiva muito longa;...: pensamento incompleto; \#: interrupção da enunciação de uma pessoa; \#\#: interrupção da enunciação de duas pessoas; (...): interrupção de uma enunciação e posterior continuação da enunciação interrompida; (não-itálico) - textos acrescentados pelo pesquisador; '..': aspas simples indicam a fala ou texto de alguém citado dentro da enunciação de outrem.

Na segunda etapa da análise ${ }^{(12)}$, chegou-se ao objeto discursivo, no qual foram empregadas as ferramentas analíticas que mostraram como funcionou o processo discursivo e os efeitos de sentidos que derivaram do discurso. Elegemos como ferramentas analíticas a metáfora, o interdiscurso, processos parafrásticos e polissemia.

A metáfora consiste na tomada de uma palavra por outra, estabelecendo o modo como ela significa. O interdiscurso é a relação do discurso com uma multiplicidade de discursos. Os processos parafrásticos evidenciam que em todo dizer há sempre algo que se mantém; a polissemia rompe com a repetição, caracterizando os múltiplos sentidos produzidos pelo sujeito, o diferente do já dito.

$\mathrm{Na}$ terceira etapa, chegou-se a formação discursiva dos seus enunciadores que denotou a formação ideológica(12) dos sujeitos.

O estudo foi aprovado pelo Comitê de Ética e Pesquisa da instituição (Protocolo no 093/2004 CEP/UFSM) e todos os participantes assinaram o Termo de Consentimento Livre e Esclarecido. Foram atribuídos nomes fictícios às mulheres participantes do estudo para garantir o anonimato das mesmas.

\section{APRESENTAÇÃO DOS RESULTADOS E DISCUSSÃO}

Para atender as múltiplas necessidades de sobrevivência e as demandas de cuidados contínuos no domicílio, as mulheres cuidadoras priorizam as ações cuidativas no seu cotidiano existencial. No espaço da DCS Corpo Saber, foi apresentada uma questão geradora ampla ("como vocês cuidam das crianças em casa?") que se desdobrou em outros dois questionamentos na condução do debate grupal: "quem a auxilia (ajuda) neste cuidado?" e "com quem vocês aprenderam a cuidar desta forma?"

Assim, a partir dos resultados, as cuidadoras desvelaram a natureza complexa do cuidado às CRIANES e a relevância de realizá-lo com base em saberes e práticas que não pertencem ao cotidiano existencial da maioria delas. Ao compartilhar suas experiências, dúvidas, inseguranças, medos e incertezas no cuidar, demarcaram o enfrentamento com um cuidado totalmente dependente de acertos e erros para garantir ou não a sobrevivência da criança. 
Tais achados conduziram para a apresentação do cuidado às CRIANES de duas formas: um cuidado (sobre)natural e um cuidado singular, sem deixarem de ser ambos culturalmente construídos.

O caráter (sobre)natural do cuidado relacionase, neste estudo, à quantidade e à intensidade de dedicação que essas crianças exigem para além da prática natural de cuidar da maioria das crianças ${ }^{(13)}$. O saber de experiência feita, que foi apreendido por essas mulheres na socialização das práticas femininas de cuidar, demonstrou insuficiência para atender a complexidade dos cuidados que os seus filhos apresentam. Com isto, elas buscam outros subsídios para sustentar suas ações cuidativas, dentre eles a força espiritual, a iluminação, a divinização, a esperança e a solidariedade. Na releitura das práticas profissionais de cuidar (equipe de enfermagem, neurologista, fisioterapeuta, fonoaudiólogo, etc.), vão tecendo um estilo próprio de realizar o seu cuidado no ambiente do domicílio, integrando esse cuidado ao cotidiano existencial ${ }^{(14)}$ e normalizando a agenda dessa criança com a sua agenda de vida.

O termo singular é empregado aqui, do latim singulare, pertencente ou relativo a um, único, particular e individual. Ou seja, algo que é especial, raro e extraordinário. Refere-se àquilo que é distinto, diferente e notável ${ }^{(15)}$. Neste sentido, entende-se a singularidade do cuidado às crianças cujas necessidades especiais de saúde são superiores às da maioria das crianças em virtude de sua fragilidade clínica. Incluem aquele cuidado que requer das mulheres cuidadoras uma prática de cuidar fundamentada em saberes científicos. O singular desse cuidado reside no fato de que, agregado à prática cotidiana de cuidar na alimentação, hidratação, promoção do conforto e bem-estar da criança, a maioria das cuidadoras de CRIANES lida com medicamentos, tecnologias corporais e extracorporais, retardo de desenvolvimento psicomotor e quadros de morbidade associados (RGE, pneumopatia crônica, sequela de meningite, hidrocefalia, etc.). Há uma necessidade contínua de aliar ao seu estilo de cuidar a prevenção de danos, a minimização de riscos, a vigilância constante dos sinais de perigo associados à manifestação da condição de base (febre, convulsão, hidrocefalia). Ou seja, a fragilidade clínica dessas crianças impõe para todas as cuidadoras a incorporação do conhecimento científico importante para o reconhecimento das mudanças no quadro clínico que podem fazer a diferença entre a vida e a morte.

Raquel, mulher cuidadora, mãe de M. (9 meses de idade) e J. ( 2 anos e 6 meses de idade), ambos com demanda mista de cuidados (demandas de cuidados de desenvolvimento, tecnológicos, medicamentosos e habituais modificados), expressa o modo como tem cuidado dos filhos no domicílio durante a apresentação de sua produção artística (PA):

(...) Assim, aqui abaixo das mãos tem uma forma que é uma banheira. Mas como um sol duas estrelas e uma banheira, vamos dizer o sabonete. (...) Eu coloquei como se fosse o desenho de um castiçal, com uma vela, raio de luz, acesa né? Abaixo aos pés, raios de gramado... no meio raios de sol, natureza energia e luz. Energias, força espiritual e material, tá? O sol representa a luz. Muita alegria, muita paz e muito amor. (...) A estrela como se fosse uma estrela guia, como eu sinto ele, como um anjo de Deus. (...). Em primeiro lugar também, buscando muito a espiritualidade, em primeiro lugar (Cuidadora Raquel).

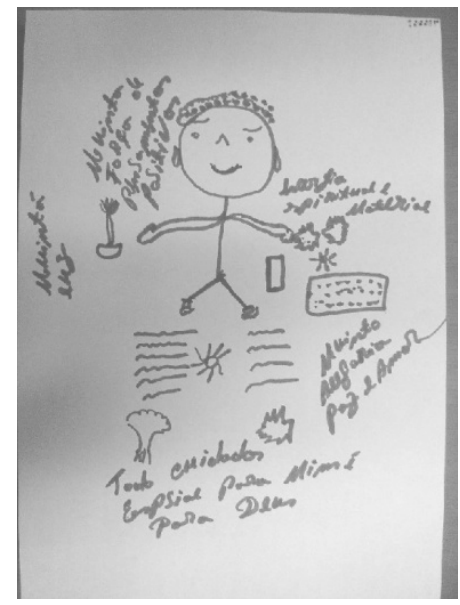

Figura 1: PA de Raquel - DCS Corpo Saber.

Enunciações metafóricas traduzem a singularidade do dito de Raquel, situando o cuidado aos filhos como algo (sobre)natural, no sentido de que exige dela um esforço para além de sua capacidade natural de cuidadora. Entretanto, o sentido apreendido em suas metáforas aponta para uma adequação do papel da mulher como cuidadora naturalizado pelo legado cultural da obrigação moral.

Assim, o termo (sobre)natural deriva de um dos significados de sobrenatural como aquilo que 
ultrapassa o natural, que não é atribuído à natureza. Dessa forma, o dito das cuidadoras foi ressignificado na construção “(sobre)natural" como algo que está além dos saberes e das práticas naturais de cuidado as crianças.

Nesse sentido, Raquel se apropria de objetos que produzem luz (sol durante o dia, velas e castiçal durante a noite) para representar uma necessidade espiritual de iluminação. Não só a luz para guiar os seus caminhos de cuidadora, mas também a energia que essa luz pode gerar associando as forças espirituais às materiais necessárias ao enfrentamento das ações cuidativas, como, por exemplo, o banho. Essas forças são também fontes geradoras de alegria, paz e amor, aspectos essenciais à tarefa de prestação do cuidado materno. Dentro deste enfoque, a dimensão subjetiva do cuidado para essa cuidadora assume um caráter metafísico e sobrenatural, sem deixar de ser culturalmente construído.

Raquel utiliza o banho como uma metáfora para apresentar a natureza complexa dos cuidados prestados às duas crianças (seus filhos) com derivação ventrículo peritoneal (DVP), uma delas com ferida aberta devido à teratoma sacrococcígeo. Os cuidados com a região de implantação do cateter de DVP e com a ferida exigem modificações no banho para evitar contaminação, danos e lesões. Percebe-se, no enunciado da cuidadora Raquel, a busca por uma força que the ampare no enfrentamento desse cotidiano marcado por desafios constantes. Ela se sustenta nos legados da obrigação moral, da tradição e da dedicação(11), aliados à espiritualidade (Deus), na luta pela sobrevivência dos filhos.
Portanto, para caracterizar esse esforço sobre humano no cuidado aos filhos, uma das cuidadoras (Raquel) se refere à luz como fonte de iluminação de suas forças físicas e espirituais. Em virtude da demanda elevada de cuidados impostos por duas CRIANES a uma só cuidadora, a crença em uma força superior ("Deus", religião, etc.) proporciona-lhe a paz de espírito, a alegria, o amor e a felicidade no enfrentamento desse cotidiano marcado por situações limites, constituindo em uma fonte de empoderamento individual. Assim, a espiritualidade é uma poderosa aliada para cuidadores de CRIANES, pois estes buscam uma significação transcendente para a situação vivenciada ${ }^{(16)}$.

A seguir, Lúcia, mulher cuidadora, mãe de $D$. (10 anos de idade), que também apresenta demanda mista de cuidados, enuncia:

(...) Eu coloquei assim umas setinhas que são os cuidado que eu tenho com a D., e são muitos cuidados mesmo!! E eu às vezes eu passo até o dia observando ela (...). Tem também o coraçãozinho dela aqui quando ela está dando convulsão ele fica acelerando demais e tem que estar cuidando (vigilante). E, às vezes, quando ela dá convulsão ela fica roxinha e o coraçãozinho dela dispara.(...) Então, aqui o nariz, eu tenho cuidado com a boca e o nariz porque tem facilidade de dá bactérias na sonda (risco de contaminação da gastrostomia) e transmite também para o pulmão (risco de infecção pulmonar). Eu passo o dia olhando aquela criança (risos). (...) quando ela nasceu eu já comecei a levar ela no neurologista e ela já me passou todos os cuidados dela (Cuidadora Lúcia).

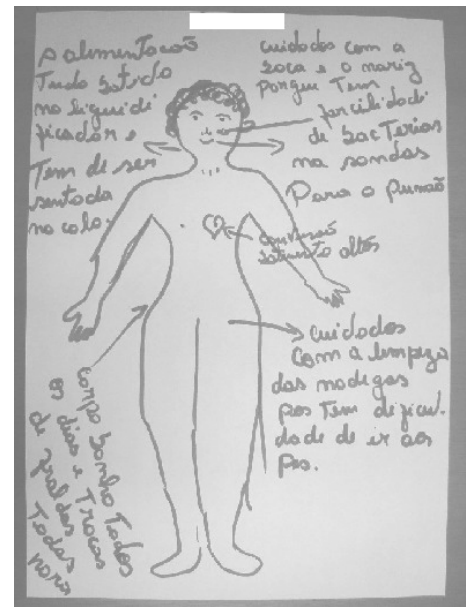

Figura 2: PA de Lúcia - DCS Corpo Saber.

Na trajetória de cuidadora de CRIANES, Lúcia enfrenta uma elevada demanda de cuidados, não só em termos de quantidade como também de intensidade ("Muitos cuidados mesmo"), desde o nascimento de D.
Lúcia destaca cuidados reais que fazem parte de seu cotidiano, os quais são muitos (quantidade), são constantes e regulares e não acabam nunca (intensidade). Estes cuidados estão presentes nas 24 horas do dia ("eu passo o dia observando ela"), sem 
vislumbrar uma possibilidade de mudança dessa realidade.

As demandas de cuidados materializam-se no enunciado da cuidadora em ações realizadas no seu cotidiano existencial, com destaque para: a) vigilância constante ("eu passo o dia olhando aquela criança"); b) mensuração da frequência cardíaca; c) monitoração dos episódios de convulsão e cianose; d) associação entre os episódios de convulsão e cianose (fica roxinha) e aceleração do batimento cardíaco; e) cuidados com a alimentação por sonda nasojejunal; f) prevenção de contaminação da sonda; g) prevenção de infecção pulmonar.

Sob a orientação do profissional neurologista, Lúcia tem conduzido esses cuidados baseando-se em tentativas mais de acerto do que erros, por vezes amedrontada com a possibilidade da infecção.

O passar o dia olhando aquela criança, simboliza a dedicação da cuidadora para atender as múltiplas demandas de cuidados da filha, ao mesmo tempo em que evidencia a fragilidade dessa criança. O legado cultural da dedicação adquire maior visibilidade, ao mesmo tempo em que revela a filiação cultural ao mito de boa mãe ${ }^{(11)}$ Ou seja, os cuidados com D. são intensos e representam uma sobre(carga) para Lúcia, sabendo que desses cuidados depende a possibilidade de sobrevivência ou não de $D$.

A singularidade no cuidado de monitoração e vigilância constante diz respeito à identificação de alterações do estado clínico da criança, como a febre e a convulsão, por exemplo. Isso implica obter informações sobre a condição diagnóstica da criança, saber o que esperar nos momentos de crises e como essas podem ser antecipadas. A falta dessas informações traz insegurança e sofrimento para as cuidadoras.

Raquel e Lúcia desenvolvem um cuidado com componentes (sobre)naturais denotando as diversas formas que cada uma encontrou de enfrentar o desafio no seu papel social de mulheres cuidadoras de CRIANES. Os saberes e práticas que fundamentam esses cuidados foram aprendidos nas relações com os médicos e enfermeiros, e apreendidos com o tempo e a intensidade de convivência com a condição da criança.

Assim, a sobrevivência das CRIANES depende diretamente do reconhecimento da necessidade de essas cuidadoras desenvolverem uma expertise ${ }^{(14)}$ no cuidado, pois não se trata apenas de cuidados básicos e naturais. Estas crianças requerem cuidados singulares por sua natureza estreitamente vinculada ao risco de morbidade e mortalidade.

Nesse sentido, a preservação da vida é a principal meta desse cuidado, de modo a atender à necessidade especial de saúde da criança. Associadas a isso, as condições materiais de existência se somam à fragilidade clínica e expõem a criança à vulnerabilidade social $^{(5)}$.
Por outro lado, Ana e Maria desenvolvem um cuidado incipiente, marcado por dúvidas e incertezas, bem como pouco acesso a informações sobre a doença, o tratamento e práticas de cuidado à criança.

Ana, mulher cuidadora de G. ( 5 meses de idade) com demanda mista de cuidados (de desenvolvimento, tecnológico, medicamentoso, habituais modificados), desenvolve suas ações cuidativas pautando-se na reprodução das práticas observadas por ela na clínica pediátrica:

Aqui eu desenhei o G., né? (...) eu sempre guardo a banheira dele já esterilizada, eu passo alquinho (álcool), isso eu estou falando em casa né? Por que aqui (no hospital) é direto com as enfermeiras. Eu boto Nistatina ${ }^{\circledR}$ no saquinho (região perineal) eu passo pouco para a pele respirar um pouco, né? (...) Troco várias vezes. (...) Por que assim quando ele estava em casa, (...) até foi um pouco falta de perguntar, eu tinha medo de pegar ele no colo (...) Já agora não, segundo o que o médico me falou, quanto mais eu pegar ele de pezinho até seria melhor pra circular o líquido (referindo-se ao líquor céfalorraquidiano drenado pela DVP), né? (...) Em casa eu olhava bastante a temperatura dele pra ver se não tinha febre, principalmente, três vezes ao dia. Também cuidava o perímetro cefálico dele pra ver se a válvula não estava entupida, também, geralmente eu que notava quando a válvula estava entupida ou infeccionada (Cuidadora Ana). 


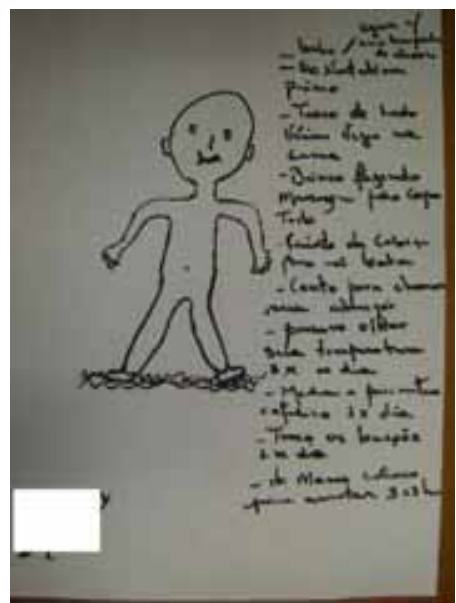

Figura 3: PA de Ana - DCS Corpo Saber.

Ana reproduz parte da linguagem científica adotada pelos profissionais de saúde no ambiente da clínica pediátrica para descrever os cuidados que têm com G. no domicílio. Entretanto, esses cuidados orientam-se para: a) a desinfecção da banheira; b) cuidados com o períneo e a troca das fraldas; c) o posicionamento; d) a vigilância da febre (três vezes ao dia); e) monitoramento da derivação ventrículoperitoneal/DVP (perímetro cefálico, risco de obstrução da válvula) e de infecções. As dificuldades oriundas da organização da vida familiar de Ana (ela tem mais cinco filhos) inviabilizaram a sua permanência com G. durante os períodos de hospitalização, distanciando-a dos cuidados profissionais de enfermagem. Neste sentido, o seu aprendizado, até então, foi mediado pelos momentos de interação social com a prática de cuidado de enfermagem profissional, o que não lhe traz segurança para cuidar de G.

Ações como desinfetar a banheira, posicionar a criança para prevenir broncoaspiração durante a alimentação e medir a temperatura corporal três vezes ao dia são representativas das preocupações das cuidadoras. Tais preocupações marcam a singularidade do cuidado às CRIANES no controle de infecções respiratórias e do sistema nervoso, pois elas são as principais responsáveis por internação de CRIANES, com uma média alta de permanência hospitalar ${ }^{(2,7,11)}$.

Maria, mulher cuidadora de A. (9 meses de idade), que possui demanda mista de cuidados, descreve os cuidados domiciliares da seguinte forma:

Esse é o A. Eu dou a mamadeira de manhã. Aí eu boto ele sentadinho, porque ele tem problema de refluxo (refluxo gastroesofágico) e de vomitar, né? Aí depois ali por 10 horas eu dou uma fruta. Depois eu dou o almoço, dou água e ele dorme pouquinho. Mas ele tem que estar sempre sentado (devido ao refluxo gastroesofágico), nunca deitado por causa do pulmão (risco de broncoaspiração), né? Eu corto as unhas dele e de tarde ali pelas cinco horas dou a janta. E é o que eu faço com ele. Aqui no hospital que ele está mamando só pela sonda (nasojejunal), tiraram toda a alimentação (por via oral), né? (Cuidadora Maria).

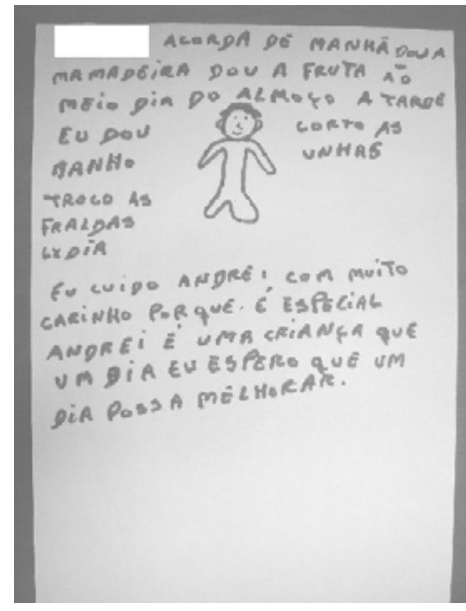

Figura 4: PA de Maria - DCS Corpo Saber.

Maria detalha o seu dia-a-dia de dedicação em casa aos cuidados com A: a) alimentação via oral (com mamadeira e frutas); b) posicionamento e vigilância de A, sempre sentado, por causa do refluxo gastroesofágico (RGE) e para evitar a 
broncoaspiração; c) hidratação; d) repouso à tarde; e) cuidado com as unhas.

Maria ressalta que, no hospital, foi retirada toda a alimentação via oral, pois ele está se alimentando pela sonda nasojejunal. Em sua fala, identifica-se um cotidiano marcado pela rotina e pelo preenchimento do tempo com ações cuidativas. Desta forma, a cuidadora não só destaca os cuidados habituais modificados que ocupam todo o seu tempo, mas também a preocupação com a manutenção da sobrevivência do filho. Neste sentido, a condição existencial de boa mãe e de cuidadora zelosa e vigilante são determinadores da dedicação total aos cuidados e pelos novos desafios que se descortinam no seu cotidiano.

Além dos cuidados habituais modificados que já tem manejado, desde o nascimento de A, Maria sabe da necessidade da sonda nasojejunal, como uma possibilidade real no retorno ao domicílio. Percebendo em Maria certo receio no tocante ao manuseio da sonda, questionei-a sobre isso. Nesse momento, Lúcia intervém, compartilhando com Maria sua vivência com o cuidado tecnológico:

Já. Já (manuseei a sonda) só que eles (os médicos) até pensaram em mandar com a sonda pra casa, mas eu fiquei com medo de lidar com a sonda, né? (com ar tímido e parecendo envergonhada) (Cuidadora Maria).

A cuidadora Lúcia, interrompendo Maria, expõe a sua vivência em lidar com a sonda:

Eu achei até melhor depois que colocou a sonda na D. Porque a D. pra eu dar comida a ela eu tinha que sentar com ela e eu passava mais de meia hora dando comida a ela. É!!! E com a sonda!!! Falar a verdade, é $100 \%$. É eu bater, deixo ali pingando e é só ficar olhando pra ela não arrancar. E ela conseguiu até alcançar o peso, né? (Cuidadora Lúcia).

Lúcia, uma cuidadora mais experiente (10 anos) em relação ao cuidado na alimentação, destaca as vantagens e desvantagens de cada método, seja por via oral ou por sonda. Neste sentido, os aspectos positivos dessa tecnologia são ressaltados, de modo a tranquilizar e apoiar Maria em um momento de incerteza. A experiência adquirida por Lúcia ao cuidar de sua filha revela, ainda, a solidariedade feminina, um dos legados transmitidos pela herança cultural.

As demandas de cuidados complexos às CRIANES evidenciadas pelo estudo incluíram as de desenvolvimento, habituais modificados, medicamentosos e no manejo da tecnologia, em acordo com estudo desenvolvido em um grupo com perfil semelhante, no município do Rio de Janeiro ${ }^{(9)}$.

Essas demandas incluem cuidados de caráter singular que são desenvolvidos, tendo por base as orientações dos profissionais de saúde (em geral, o médico e a enfermeira no hospital) e se estruturam no sentido de atender a todas as necessidades de cuidados das CRIANES. Essas demandas de cuidado, que são mistas para a maioria delas, representam uma sobrecarga no cotidiano da mulher cuidadora que dedica sua agenda diária ao cuidar.

Com o intuito de apresentar os cuidados (sobre)naturais mencionados por essas quatro cuidadoras e sua ressignificação como cuidados singulares, foi elaborado o Quadro 1: 
Quadro 1: Os cuidados (sobre)naturais e sua ressignificação em cuidados singulares. DCS Corpo Saber - 2004.

Cuidados (sobre) naturais - físico-clínicos

\begin{tabular}{|c|c|c|c|c|}
\hline \multicolumn{4}{|l|}{ Cuidadoras } & \multirow{2}{*}{$\begin{array}{l}\text { Cuidados } \\
\text { singulares }\end{array}$} \\
\hline Raquel & Lúcia & Ana & Maria & \\
\hline $\begin{array}{l}\text { Apropriação de objetos } \\
\text { que produzem luz (sol } \\
\text { durante o dia e velas e } \\
\text { castiçal durante a noite) } \\
\text { para representar uma } \\
\text { necessidade espiritual de } \\
\text { iluminação. }\end{array}$ & $\begin{array}{l}\text { Vigilância } \\
\text { constante. }\end{array}$ & $\begin{array}{l}\text { Desinfecção da } \\
\text { banheira. }\end{array}$ & $\begin{array}{l}\text { Alimentação via oral } \\
\text { (com mamadeira e } \\
\text { frutas). }\end{array}$ & $\begin{array}{l}\text { Higiene } \\
\text { Períneo } \\
\text { Unhas } \\
\text { Troca das fraldas }\end{array}$ \\
\hline \multirow{6}{*}{$\begin{array}{l}\text { Fontes geradoras de } \\
\text { empoderamento } \\
\text { individual: cuidar com } \\
\text { alegria, paz e amor. }\end{array}$} & $\begin{array}{l}\text { Mensuração da } \\
\text { frequência } \\
\text { cardíaca. }\end{array}$ & $\begin{array}{l}\text { Cuidados perineais e } \\
\text { a troca das fraldas. }\end{array}$ & $\begin{array}{l}\text { Posicionamento de } \\
\text { A, sempre sentado, } \\
\text { por causa do RGE. }\end{array}$ & $\begin{array}{l}\text { Alimentação } \\
\text { SNJ } \\
\text { Via oral }\end{array}$ \\
\hline & $\begin{array}{l}\text { Monitoração dos } \\
\text { episódios de } \\
\text { convulsão e } \\
\text { cianose. }\end{array}$ & $\begin{array}{l}\text { O posicionamento } \\
\text { da criança. }\end{array}$ & Hidratação. & $\begin{array}{l}\text { Hidratação } \\
\text { Posicionamento } \\
\text { da criança } \\
\text { Sentado para } \\
\text { proporcionar } \\
\text { conforto (RGE) } \\
\text { Prevenção de } \\
\text { broncoaspiração } \\
\text { Drenagem do LCR } \\
\text { na DVP }\end{array}$ \\
\hline & $\begin{array}{l}\text { Associação entre } \\
\text { episódios de } \\
\text { convulsão, } \\
\text { cianose e } \\
\text { aceleração do } \\
\text { batimento } \\
\text { cardíaco. }\end{array}$ & $\begin{array}{l}\text { A vigilância da febre } \\
\text { (três vezes ao dia). }\end{array}$ & Repouso à tarde. & $\begin{array}{l}\text { Prevenção de } \\
\text { infecção } \\
\text { Pulmonar } \\
\text { Contaminação da } \\
\text { SNJ } \\
\text { Contaminação do } \\
\text { cateter da DVP }\end{array}$ \\
\hline & $\begin{array}{l}\text { Cuidados na } \\
\text { alimentação por } \\
\text { sonda nasojejunal } \\
(\mathrm{SNJ}) \text {. }\end{array}$ & $\begin{array}{l}\text { Monitoramento da } \\
\text { DVP para drenagem } \\
\text { do líquor } \\
\text { céfalorraquidiano } \\
\text { (LCR). }\end{array}$ & $\begin{array}{l}\text { Vigilância constante } \\
\text { do posicionamento } \\
\text { da criança para } \\
\text { evitar a } \\
\text { broncoaspiração. }\end{array}$ & \multirow[t]{3}{*}{$\begin{array}{l}\text { Monitoração } \\
\text { Sinais Vitais } \\
\text { Episódios } \\
\text { convulsivos } \\
\text { Funcionamento da } \\
\text { DVP }\end{array}$} \\
\hline & $\begin{array}{l}\text { Prevenção de } \\
\text { contaminação da } \\
\text { sonda. }\end{array}$ & \multirow[t]{2}{*}{$\begin{array}{l}\text { Monitoramento de } \\
\text { infecções. }\end{array}$} & \multirow[t]{2}{*}{$\begin{array}{l}\text { Cuidado com as } \\
\text { unhas. }\end{array}$} & \\
\hline & $\begin{array}{l}\text { Prevenção de } \\
\text { infecção } \\
\text { pulmonar. }\end{array}$ & & & \\
\hline
\end{tabular}

A singularidade do cuidado na alimentação de uma criança com sonda nasojejunal implica o conhecimento técnico-científico desde o preparo do alimento até a sua administração. Durante o preparo, ela precisa ser coccionada, liquidificada, coada, observando medidas para evitar a contaminação. O posicionamento da criança prévio à administração da dieta líquida por SNJ, a mensuração do resíduo gástrico, o cálculo do que será infundido descontando-se o volume residual mensurado, a devolução do resíduo gástrico por infusão lenta. Além disso, é imperativo a monitoração de intercorrências que podem acontecer, durante esse procedimento (regurgitação, vômito, broncoaspiração), além da infusão lenta da dieta por gravidade, a limpeza da
SNJ após a administração do volume da dieta com água filtrada e fervida ${ }^{(17)}$. Tudo isso se constitui em etapas que exigem aplicação dos princípios da enfermagem fundamental, da matemática, da nutrição humana, da física, etc., aliados à paciência e à atenção da cuidadora.

A alimentação por via oral de uma criança com RGE possui implicações como, por exemplo: medidas preventivas da contaminação do alimento, bem como a observação da consistência pastosa deste, posicionamento da criança para prevenir broncoaspiração e pneumonia(17).

O cuidado singular na prevenção de infecções implica a monitoração da temperatura como uma das primeiras manifestações visíveis de contaminação do 
cateter de DVP, da SNJ, da ferida (do estoma), de broncopneumonia ou pneumonia por aspiração. No sentido de prevenir infecções, faz-se necessário empreender medidas para evitar a contaminação no preparo dos alimentos, no manejo do cateter de DVP e da SNJ.

O posicionamento da criança em semifowler (sentado com apoio a 45 graus) foi uma ação cuidativa adotada na prevenção de broncoaspiração de alimentos administrados por via oral na condição de RGE e pela SNJ (dieta líquida). Na presença de DVP, essa ação direciona-se para a manutenção da permeabilidade do cateter, possibilitando a drenagem do $\operatorname{LCR}^{(17)}$.

A baixa escolaridade, comum a maioria as cuidadoras de CRIANES $^{(7)}$, pode dificultar a apreensão de conhecimentos científicos que embasem a realização desses cuidados complexos. Sabe-se que há uma estreita relação entre escolaridade materna e saúde infantil( ${ }^{(3)}$ que se agrava quando associada à presença de condições especiais de saúde da criança.

A singularidade na modificação dos cuidados habituais envolve medidas de proteção do períneo e da ferida do teratoma sacrococcígeo, durante a higienização, de modo a minimizar danos. Envolve também atenção especial para o posicionamento e o banho da criança, que possui dispositivos tecnológicos no corpo, como SNJ, cateter de oxigênio, válvulas etc., devido ao risco de penetração de água no sítio de implantação da válvula, da entrada de ar ou água no estômago da criança pelo orifício da sonda não fechada e do deslocamento da SNJ. Envolve, por fim, atenção à hidratação da criança em uso de SNJ, com pneumopatia crônica, bem como a necessidade de monitorar os sinais de desidratação nos eventos de dispnéia/taquipnéia contínua.

O desenvolvimento de habilidade no cuidado à criança com cateter de oxigênio, com válvula de DVP, com SNJ envolve uma singularidade no manejo dessas tecnologias corporais implantadas, o que causa insegurança na mulher cuidadora. Ela precisa conhecer, por exemplo, o mecanismo de funcionamento de uma válvula de DVP para monitorar a sua não funcionalidade e/ou presença de infecções.

Assim, as cuidadoras de CRIANES desenvolvem no domicílio um cuidado de sobrevivência, o que torna este cuidar um acontecimento singular em suas vidas. Esses cuidados são complexos, portanto, não pertencentes ao cotidiano das famílias e ao saber oriundo de sua cultura. Estudo desenvolvido com crianças soropositivas para o HIV denotou os desafios de suas cuidadoras em tornar o cuidado medicamentoso parte de seu cotidiano de cuidar ${ }^{(18)}$

Embora todas as crianças apresentem demanda de cuidado medicamentoso, este não foi incluído pelas cuidadoras no "corpo" desenhado nem mencionado como parte constitutiva do seu cotidiano de cuidados. Dessa forma, esse não-dito pode ser significado, por sua não referência, como algo silenciado(18).

Uma das possíveis explicações para esse silêncio é o fato de as cuidadoras não participarem do cuidado medicamentoso durante a permanência da criança no hospital; além disso, a DCS Corpo Saber ocorreu no espaço hospitalar durante o período de internação de seus filhos. A memória recente da hospitalização silenciou o cuidado medicamentoso, pois, na unidade de internação pediátrica, a equipe de enfermagem é responsável por esses cuidados. A memória latente dos cuidados domiciliares explicitou os demais tipos de cuidados (tecnológicos, habituais modificados e de desenvolvimento), pois muitas das ações a eles relacionadas são delegadas aos acompanhantes no hospital. Em geral, somente os cuidados relativos à alimentação, à higiene e à recreação da criança são delegados aos familiares acompanhantes durante a internação.

Dessa forma, a pouca participação da família no planejamento e na implementação dos cuidados às crianças no espaço hospitalar, incluindo o medicamentoso, pode estar se refletindo nas rehospitalizações frequentes da criança. Essa exclusão no ambiente hospitalar não permite que elas tenham contato com as práticas de cuidar que terão de reproduzir no domicílio, especialmente aquelas que envolvem os saberes fundamentais de enfermagem, os princípios da matemática ${ }^{(14)}$.

Do mesmo modo, visualiza-se uma pouca participação da enfermagem no seguimento ambulatorial e domiciliar dessas crianças, tendo em vista que a enfermeira não foi citada pelas cuidadoras como mediadora de práticas cuidativas durante essa DCS e, o mesmo se verificou em outros estudos relativos a essa clientela ${ }^{(2,11)}$. Assim, percebe-se que a prática de cuidados fundamentais pautada nos saberes da enfermagem não está sendo mediada com os familiares cuidadores, sendo que os profissionais citados foram o médico e o fisioterapeuta. Portanto, o suporte para o cuidado no domicílio não está tendo visibilidade, nem efetividade. Neste sentido, destacam-se estudos que tem ressaltado a importância da ação educativa associada à ação curativa, como um fator contribuinte para a redução das internações hospitalares $^{(5,13-14,18-19)}$.

Outra forma de silêncio manifesto foi a não menção à atividade de recreação como integrante da dimensão subjetiva do cuidar de CRIANES no domicílio. Deste modo, percebe-se que a preocupação das cuidadoras centra-se na implementação de cuidados de sobrevivência fundamentado na preservação da vida da criança. O significado desse não-dito sugere que a socialização 
da criança situa-se à margem do processo de cuidar. Com isso, percebe-se não somente o isolamento da criança, mas também o isolamento social da mulher cuidadora, dificultando o seu processo de empoderamento coletivo.

Assim, o modo de cuidar dessas CRIANES envolve cuidados singulares de natureza complexa, contínua e intensa. As cuidadoras fazem um esforço sobre-humano para suprir as demandas das crianças e garantir a sobrevivência delas. Entretanto, esses cuidados envolvem conhecimentos de enfermagem que precisam ser mediados nas atividades de interação dos profissionais de enfermagem com as cuidadoras em diferentes cenários de prática (ambulatório, hospital, comunidade, domicílio, etc.). Incluir as famílias com o intuito de compartilhar saberes e práticas necessários ao desenvolvimento deste cuidado (sobre)natural e singular no domicílio apresenta-se como um dos desafios para a Enfermagem Pediátrica.

Nessa rotina de cuidados de sobrevivência, algumas delas acabam se resignando e buscando a normalização da vida conforme ela se apresenta, considerando que seu cotidiano é dedicado única e exclusivamente a esta atividade. Isto leva ao fortalecimento do empoderamento individual e a sua alienação ${ }^{(11,20)}$, pois, em se tratando de um cuidado de sobrevivência, essas cuidadoras não tem escolha, tendo, muitas vezes que manipular de forma compulsória, tecnologias estranhas ao cotidiano familiar $^{(11,18)}$. Para elas, o desempenho do papel de cuidadoras constitui-se uma obrigação materna de ordem moral, implementando ações cuidativas preservadoras da vida de seus filhos.

\section{CONCLUSÕES E IMPLI CAÇões PARA A PRÁtICA CLÍ NICA}

Na dimensão subjetiva, o cuidado às CRIANES se dá de duas formas: (sobre)natural e singular. Visualizou-se, na natureza complexa desse cuidado, a relevância de sua realização com base em saberes e práticas que não pertencem ao cotidiano existencial da maioria das cuidadoras. Em verdade, são saberes pertencentes ao campo dos cuidados de enfermagem pediátrica que penetram no universo da família e se somam ao conjunto dos cuidados que todas as crianças possuem independente do seu estado de saúde.

Paradoxalmente, o fato de esses cuidados serem intensos, constantes, contínuos e complexos pode transformar-se em fonte geradora de estresse e opressão a sua cuidadora que se sente responsável por esse cuidado. Nesse sentido, por ser um cuidado de sobrevivência, elas sentem-se afetivamente comprometidas com os cuidados aos filhos e moralmente obrigadas a desenvolvê-los para não ser alvo de crítica da sociedade e da instituição de saúde. Com isso, elas se resignam ao desempenho do papel de cuidadoras e a implementação de ações cuidativas preservadoras da vida de seus filhos.

Assim, as CRIANES são um grupo emergente que apresenta desafios a Enfermagem Pediátrica, tendo em vista as diferentes demandas de cuidados tanto em nível hospitalar quanto familial e comunitário. Apresentam desafios, também, as suas famílias no que tange a quantidade e natureza dos cuidados desenvolvidos no domicílio.

Dessa forma, incluir essas crianças e suas famílias na assistência de enfermagem torna-se fundamental no sentido de que a enfermagem possa contribuir com seus saberes fundamentais e suas práticas de cuidados científicas para ampliar o poder de negociação das mulheres no cuidado às CRIANES para além da sobrevivência.

Ressalta-se também a necessidade da criação de programas de acompanhamento das famílias das CRIANES, tais como grupos de apoio e educação em saúde bem como a necessidade de fomentar a rede de suporte social com o intuito de se reduzirem os índices de reinternações e a demanda aos serviços de saúde especializados.

\section{REFERÊNCI AS}

1. Secretaria Executiva, Ministério da Saúde. Sistema Único de Saúde - SUS. [Internet] Brasília (Brasil): Ministério da Saúde; 1990 [cited 2006 out 16]. Available

from:

http://portal.saude.gov.br/portal/arquivos/pdf/LEI 808 0.pdf.

2. DATASUS [Internet]. Brasília: Ministério da Saúde (BR) [cited 2009 mai 12]. Departamento de Informática do SUS - DATASUS. Available from: http://tabnet.datasus.gov.br/cgi/idb2006/matriz.htm 3. Macinko J, Guanais FC, Souza MFM. Evaluation of the impact of the Family Health Program on infant mortality in Brazil, 1990-2002. J Epidemiol Community Health. 2006; 60(1): 13-19.

4. McPherson MG, Arango P, Fox $H$, Lauver $C$, McManus $M$, Newachek PW, et al. A new definition of children with special health care needs. Pediatrics. 1998; 102(1); 137-41.

5. Neves, ET, Cabral IE. A fragilidade clínica e a vulnerabilidade social das crianças com necessidades especiais de saúde. Rev. gaúcha enferm. 2008;29(2): 139-51.

6. Cabral IE. Aliança de saberes no cuidado e estimulação da criança-bebê: concepções de estudantes e mães no espaço acadêmico de enfermagem. Rio de Janeiro: Editora da Escola de Enfermagem Anna Nery; 1999. 298 p.

7. Vernier ETN, Cabral IE. Caracterização de crianças com necessidades especiais de saúde e seus familiares cuidadores, Santa Maria (RS), 2004-2005: subsídios para intervenções de enfermagem. Revista da Sociedade Brasileira de Enfermeiros Pediatras. 2006; 6(1): 37-45. 
8. Cabral IE, Moraes JRMM, Santos FF. O egresso da terapia intensiva neonatal de três instituições públicas e a demanda de cuidados especiais. Esc. Anna Nery. 2003; 7(2):211-8.

9. Cabral IE, Silva JJ, Zillmann DO, Moraes JR, Rodrigues EC. A criança egressa da terapia intensiva na luta pela sobrevida. Rev Bras Enferm. 2004; 57(1): 35-9.

10. Cunha SR, Cabral IE. As condições de vida da criança dependente de tecnologia. Revista da Sociedade Brasileira de Enfermeiros Pediatras. 2002;2(1): 87-100.

11. Vernier ETN. O empoderamento de cuidadoras de crianças com necessidades especiais de saúde: interfaces com o cuidado de enfermagem [thesis]. Rio de Janeiro: Escola de Enfermagem Anna Nery/UFRJ; 2007. 172 p.

12. Orlandi EP. Análise de Discurso: princípios e procedimentos. 6th ed. São Paulo: Pontes; 2005. $100 \mathrm{p}$.

13. Neves ET, Cabral IE. Empoderamento da mulher cuidadora de crianças com necessidades especiais de saúde. Texto contexto-enferm. 2008; 17(3):552-60.

14. Aguiar RCB. Saberes e práticas de familiares cuidadores no cuidado à criança em terapia anticonvulsivante: o processo de produção do almanaque. [dissertation]. Rio de Janeiro: Escola de Enfermagem Anna Nery/UFRJ; 2005. 147 p.

15. Ferreira $A B H$. Novo dicionário Aurélio da língua portuguesa. 3th ed. São Paulo: Positivo; 2004. 2120 p.

16. Marshall ES, Olsen SF, Mandleco BL, Dyches TT, Allred KW, Sansom N. "This is a spiritual experience": perspective of Latter-Day-Saint families living with a child with disabilities. Qual Health Res. 2003; 13(1); 57-76.

17. Hockenberry MJ, Wilson D, Winkelstein ML. Wong Fundamentos da enfermagem pediátrica. 7th ed. Rio de J aneiro: Elsevier; 2006. 1344 p.

18. Gomes AMT, Cabral IE. O cuidado medicamentoso à criança com HIV: desafios e dilemas de familiares cuidadores. Rev Bras Enferm. 2009; 62(2): 252-7.

19. Silva FD, Cabral IE. O cuidado de enfermagem ao egresso da terapia intensiva: reflexos na produção científica nacional de enfermagem pediátrica na década de 90. Rev. Eletr. Enf. [Internet]. 2001 [cited 2009 mai 12];3(2). Available from: http://www.fen.ufg. br/revista/revista3_2/cuidado.html 20. Freire P. Conscientização: teoria e prática da libertação. Rio de Janeiro: Paz e Terra; 1980. 116 p.

Artigo recebido em 18.08.08

Aprovado para publicação em 28.05.09.

Artigo publicado em 30.09.09. 